\title{
Balanced Salt Solution for Metabolic Acidosis in ICU
}

\author{
Samir Samal ${ }^{1} \odot$, Shakti B Mishra ${ }^{\odot} \odot$
}

Keywords: Balanced salt solutions, Intensive care, Metabolic acidosis, Ringer's lactate, Sepsis.

Indian Journal of Critical Care Medicine (2021): 10.5005/jp-journals-10071-23726

To the Editor,

We read with interest the original article by Rawat et al. titled "Comparison of commercially available balanced salt solution and Ringer's lactate on extent of correction of metabolic acidosis in critically ill patients". ${ }^{1}$ This is an important topic for all critically ill patients. We would like to highlight the following points:

1. The basis of assuming the time taken to the correction of metabolic acidosis with the administration of Ringer's lactate $(\mathrm{RL})$ as 60 minutes and the assumed correction time of 48 minutes in patients receiving acetate solution (AC). Most of the studies to date have shown comparable acidosis correction using either RL or AC solution.

2. The basis of the consideration that only half of the patients will have the correction of metabolic acidosis with fluid resuscitation alone is also not mentioned. It is not mentioned if it meant that patients did not receive any antibiotics or vasopressor support in the meantime (during the fluid resuscitation).

3. The time to study the effect is very small to find any difference in the effects of the fluids ( $2 \mathrm{hrs}$ ). Moreover, it is not mentioned if the patients were directly admitted to Medicine, Intensive Care Unit, or received any prior care-fluids, bicarbonates, or antibiotics in casualty, emergency room (ER), or ward.

4. They have also not mentioned the hemodynamic status or blood pressure of the patients on admission.

5. They have also not mentioned if any inotrope or vasopressor support was needed for any of the patients, as the use of such agents could have helped in the improvement of patients' arterial blood gas (ABG) parameters. ${ }^{2}$

6. It would have been helpful if antibiotic initiation within the first hour was mentioned as most of the patients were in Medicine, Intensive Care Unit, and had sepsis. ${ }^{3,4}$

\footnotetext{
1,2Department of Critical Care Medicine, IMS and SUM Hospital, Bhubaneswar, Odisha, India
}

Corresponding Author: Shakti B Mishra, Department of Critical Care Medicine, IMS and SUM Hospital, Bhubaneswar, Odisha, India, Phone: +91 6742540773, e-mail: shaktimishra84@gmail.com

How to cite this article: Samal S, Mishra SB. Balanced Salt Solution for Metabolic Acidosis in ICU. Indian J Crit Care Med 2021;25(2):236.

Source of support: Nil

Conflict of interest: None

\section{OrCID}

Samir Samal @i https://orcid.org/0000-0002-2496-1434

Shakti B Mishra 이 https://orcid.org/0000-0001-6634-1877

\section{References}

1. Rawat N, Sahni N, Yaddanapudi L. Comparison of commercially available balanced salt solution and Ringer's lactate on extent of correction of metabolic acidosis in critically ill patients. Indian J Crit Care Med 2020;24(7):539-543. DOI: 10.5005/ jp-journals-10071-23488.

2. Scheeren TWL, Bakker J, De Backer D, Annane D, Asfar P, Christiaan Boerma E, et al. Current use of vasopressors in septic shock. Ann Intensive Care 2019;9:20. DOI: 10.1186/s13613-019-0498-7.

3. Liu VX, Fielding-Singh V, Greene JD, Baker JM, Iwashyna TJ, Bhattacharya J, et al. The timing of early antibiotics and hospital mortality in sepsis. Am J Respir Crit Care Med 2017;196(7):856-863. DOI: $10.1164 / \mathrm{rccm} .201609-18480 \mathrm{C}$.

4. Levy MM, Evans LE, Rhodes A. The surviving sepsis campaign bundle: 2018 update. Intensive Care Med 2018;44(6):925-928. DOI: 10.1007/ s00134-018-5085-0.

\footnotetext{
() Jaypee Brothers Medical Publishers. 2021 Open Access This article is distributed under the terms of the Creative Commons Attribution 4.0 International License (https://creativecommons.org/licenses/by-nc/4.0/), which permits unrestricted use, distribution, and non-commercial reproduction in any medium, provided you give appropriate credit to the original author(s) and the source, provide a link to the Creative Commons license, and indicate if changes were made. The Creative Commons Public Domain Dedication waiver (http://creativecommons.org/publicdomain/zero/1.0/) applies to the data made available in this article, unless otherwise stated.
} 